\section{NOTE}

\footnotetext{
${ }^{1}$ Institut für Angewandte Mikrobiologie, JustusLiebig-Universität Giessen, IFZ-Heinrich-Buff-Ring 26-32, D-35392 Giessen, Germany

2 Institut für Bakteriologie, Mykologie und Hygiene, Veterinärmedizinische Universität, A-1210 Vienna, Austria

${ }^{3}$ Institut für Mikrobiologie und Genetik, Universität Wien, A-1030 Vienna, Austria
}

\title{
Sphingopyxis witflariensis sp. nov., isolated from activated sludge
}

\author{
Peter Kämpfer, ${ }^{1}$ Reinhard Witzenberger, ${ }^{1}$ Ewald B. M. Denner, ${ }^{3}$ \\ Hans-Jürgen Busse ${ }^{2,3}$ and Alexander Neef ${ }^{1}$
}

Author for correspondence: Peter Kämpfer. Tel: +49 64199 37352. Fax: +49 6419937359.
e-mail: peter.kaempfer@agrar.uni-giessen.de

Classification of strain $\mathbf{W}-\mathbf{5 0}^{\top}$, which was isolated from a wastewater treatment plant, was investigated by a polyphasic approach. Cells of strain $\mathrm{W}-50^{\top}$ were Gram-negative, strictly aerobic, oxidase-positive and yellow-pigmented. Ubiquinone Q-10 was the main respiratory lipoquinone system and polar lipid fingerprints were characterized by the presence of a sphingoglycolipid, suggesting that strain $\mathrm{W}-50^{\top}$ belongs to the $\alpha-4$ subclass of the Proteobacteria. Sequencing and comparative analyses of the 16S rRNA gene of strain W-50' supported its chemotaxonomic allocation as an $\alpha-4$ proteobacterium. The most closely related established taxa were species of the genus Sphingopyxis, including Sphingopyxis macrogoltabida (97.3\% similarity) and Sphingopyxis terrae (96.4\% similarity), and Sphingomonas taejonensis (97.3\%). These findings were supported by both the polyamine content, which consisted mainly of spermidine [12.9 $\left.\mu \mathrm{mol}(\mathrm{g} \mathrm{dry} \mathrm{wt})^{-1}\right]$, and the presence of 2-OH 14:0, 2$\mathrm{OH} \mathrm{15:0}$ and 2-OH 16:0 in the cellular fatty acid profile. DNA-DNA hybridization experiments resulted in similarity values of $31.9 \%$ between strain $\mathrm{W}-50^{\top}$ and Sphingopyxis macrogoltabida IFO $15033^{\top}, 44.9 \%$ between strain $\mathrm{W}-50^{\top}$ and Sphingopyxis terrae IFO $15098^{\top}$ and $31.0 \%$ between strain $\mathrm{W}-50^{\top}$ and Sphingomonas taejonensis KCTC 2884'. Based upon results obtained by detailed physiological/biochemical testing and previously published molecular evidence, strain $\mathrm{W}-\mathbf{5 0}^{\top}$ was clearly distinguishable from all other Sphingopyxis species. For these reasons, the creation of a novel species, Sphingopyxis witflariensis sp. nov., is proposed; strain $\mathrm{W}-50^{\top}$ ( $=$ DSM $14551^{\top}=$ CIP $107174^{\top}$ ) is the type strain.

Keywords: activated sludge, $\alpha$-Proteobacteria, Sphingopyxis witflariensis, polyphasic taxonomy

In recent years, studies on bacterial isolates from various environments have resulted in a significant increase in our knowledge of organisms grouped in the genus Sphingomonas sensu lato (Yabuuchi et al., 1990). Sphingomonads are strictly aerobic, chemoheterotrophic, Gram-negative bacteria that are of biotechnological interest not only because of their degradation capabilities for various xenobiotic substances, but also for their potential to produce exopolysaccharides (for reviews see White et al., 1996; Pollock, 1993). In aquatic habitats, sphingomonads have been

Abbreviations: $p N A, p$-nitroanilide; $p N P, p$-nitrophenyl.

The EMBL accession number for the 16S rRNA gene sequence of strain $\mathrm{W}-50^{\top}$ is AJ416410. found in significant numbers in drinking water (Koskinen et al., 2000), but they are also rather abundant in activated sludges, accounting for 5-10\% of the total cells (Neef et al., 1999). The interest in these organisms has led to an increase in the number of species $(>20)$ in the last few years. It has also recently become obvious from $16 \mathrm{~S}$ rDNA data that the established species of the genus Sphingomonas can be grouped into at least four clusters. As a consequence, a subdivision of the genus Sphingomonas sensu lato has been proposed very recently: the genus name Sphingomonas was retained for the cluster containing the type species of the genus Sphingomonas, Sphingomonas paucimobilis (Takeuchi et al., 2001). For the other three clusters of Sphingomonas, the new genera Sphingobium, Novosphingobium and Sphingopyxis 
have been proposed. In addition to these phylogenetic findings, some chemotaxonomic and further phenotypic features have provided evidence that the four Sphingomonas clusters represent separate genera (Busse et al., 1999; Takeuchi et al., 2001).

To clarify the actual taxonomic position of a yellowpigmented bacterial strain (designated $\mathrm{W}-50^{\mathrm{T}}$ ), which was previously isolated from a wastewater treatment plant and showed a positive signal with a Sphingomonas sensu lato group-specific oligonucleotide probe, SPH120 (Neef et al., 1999), a detailed polyphasic approach was applied.

Strain $\mathrm{W}-50^{\mathrm{T}}$ was isolated from activated sludge collected from a wastewater treatment plant in Wetzlar (Germany) by standard plating on 10-fold-diluted PTYG agar (Balkwill \& Ghiorse, 1985) containing $16 \mathrm{mg}$ aztreonam $1^{-1}$ (ICN Biomedicals). The agar plate was incubated at $20^{\circ} \mathrm{C}$ for 4 days. Further cultivation was done on R2A agar (Oxoid) at $25^{\circ} \mathrm{C}$. Cell morphology of strain $\mathrm{W}-50^{\mathrm{T}}$ was examined by light microscopy using a Zeiss Axioplan II microscope with cultures grown in liquid 10-fold-diluted PTYG medium for $24 \mathrm{~h}$ at $28^{\circ} \mathrm{C}$. The Gram reaction was tested according to standard procedures (Gerhardt et al., 1994). Oxidase activity was tested with BactidentOxidase test strips (Merck). Initial phenotypic characterization was performed using the API 20NE gallery (bioMérieux), as well as by conventional testing as described previously (Denner et al., 2001), including tests for: catalase activity, oxidative/fermentative glucose metabolism, nitrate reduction, $\mathrm{H}_{2} \mathrm{~S}$ production, citrate utilization, indole production, urease activity and the methyl red/Voges-Proskauer reaction. In addition, a detailed substrate utilization profile has been obtained as described previously by Kämpfer $e t$ al. (1991). The sensitivity of strain $\mathrm{W}-50^{\mathrm{T}}$ to antimicrobial substances was tested in the manner described by Denner et al. (2001) on Iso-Sensitest agar (Oxoid) using antibiotic-impregnated disks (Oxoid). Antibiotics tested were as follows [ $\mu$ g (unless stated otherwise) antibiotic per disk in parentheses]: ampicillin (10), amoxycillin/clavulanic acid (30), chloramphenicol (30), colistin sulfate (10), gentamicin (10), furazolidone (10), fusidic acid (10), nitrofurantoin (100), kanamycin (30), streptomycin (10), penicillin G (10 IU), bacitracin (10), polymyxin B (300 IU) and tetracycline (30).

Standard bacteriological characterization revealed that strain $\mathrm{W}-50^{\mathrm{T}}$ is a Gram-negative, oxidase- and catalase-positive, aerobic, non-spore-forming, motile $\operatorname{rod}(0.5-0.8 \times 1.0-2.0 \mu \mathrm{m})$ with a respiratory metabolism. The acetone-extracted yellow pigment of strain $\mathrm{W}-50^{\mathrm{T}}$ had the same spectral characteristics $\left(\lambda_{\max }\right.$ at 452 and $478 \mathrm{~nm}$ ) as those described for the carotenoid nostoxanthin (Jenkins et al., 1979). After $48 \mathrm{~h}$ incubation at $25^{\circ} \mathrm{C}$, strain $\mathrm{W}-50^{\mathrm{T}}$ formed circular, entire, convex, smooth and bright-yellow-pigmented colonies (diameter approx. $1 \mathrm{~mm}$ ). No growth was observed within 14 days at $42^{\circ} \mathrm{C}$, but growth was good at 15,20 , 25, 30 and $37^{\circ} \mathrm{C}$. Strain $\mathrm{W}-50^{\mathrm{T}}$ did not grow on
Table 1. Morphological and physiological characteristics of Sphingopyxis species and related organisms

Strains: 1 , strain $\mathrm{W}-50^{\mathrm{T}} ; 2$, Sphingopyxis macrogoltabida IFO $15033^{\mathrm{T}}$ (data from Kämpfer et al., 1997); 3, Sphingopyxis terrae IFO $15098^{\mathrm{T}}$ (Kämpfer et al., 1997); 4, Sphingomonas taejonensis JSS54 ${ }^{\mathrm{T}}$ (Lee et al., 2001). All strains are positive for assimilation of D-glucose. All strains are negative for: nitrate reduction; gelatin hydrolysis; assimilation of $N$-acetyl D-glucosamine, adipate, citrate, gluconate, D-mannose, Dmelibiose, rhamnose and salicin; and oxidative acid production from glycerol and rhamnose.

\begin{tabular}{|lcccc|}
\hline Characteristic & $\mathbf{1}$ & $\mathbf{2}$ & $\mathbf{3}$ & $\mathbf{4}$ \\
\hline Colony colour* & $\mathrm{Y}$ & $\mathrm{Y}$ & $\mathrm{Y}$ & $\mathrm{PY}$ \\
Aesculin hydrolysis & - & + & + & + \\
Assimilation of: & & & & \\
$\quad$ Caproate & - & - & - & + \\
L-Arabinose & - & + & - & - \\
Malate & - & - & + & + \\
Maltose & + & + & - & - \\
\hline
\end{tabular}

*Y, Yellow; PY, pale yellow.

MacConkey agar (Merck) or Czapek-Dox agar (Oxoid). Nitrate was not reduced to nitrite or $\mathrm{N}_{2}$, either in the conventional test or in the API 20NE gallery. This result was essentially in accordance with the results of Takeuchi et al. (2001), who reported nitrate reduction by members of the genera Sphingomonas sensu stricto and Novosphingobium, but no nitrate reduction by members of the genera Sphingobium and Sphingopyxis. Furthermore, $\mathrm{H}_{2} \mathrm{~S}$ production, growth on Simmons citrate agar, indole production, urease, arginine dihydrolase and hydrolysis of gelatin, starch and DNA were all negative. Strain $\mathrm{W}-50^{\mathrm{T}}$ did not produce acid from various sugars and related compounds, but D-glucose, Dmaltose, azelate, DL-3-hydroxybutyrate, suberate, Lalanine, L-histidine, L-leucine and L-proline were utilized as sole sources of carbon. Also, some of the tested $p$-nitrophenyl $(p \mathrm{NP})$ and $p$-nitroanilide ( $p$ NA) derivatives were positive, e.g. $p \mathrm{NP} \alpha$-D-glucopyranoside, bis- $p$ NP phosphate, $p$ NP phosphorylcholine, 2-deoxythymidine- $2^{\prime}-p \mathrm{NP}$ phosphate, L-alanine $p \mathrm{NA}$, L-glutamate- $\gamma$-3-carboxy $p$ NA and L-proline $p$ NA. Hydrolysis of ONPG was negative. The organism was susceptible to amoxycillin/clavulanic acid, ampicillin, colistin sulfate, gentamicin, kanamycin and polymyxin B. It exhibited resistance to bacitracin, chloramphenicol, furazolidone, fusidic acid, nitrofurantoin, penicillin G, streptomycin and tetracycline. Additional phenotypic features are shown in Table 1 and are included in the formal species description below.

Analysis of the cellular fatty acids of strain $\mathrm{W}-50^{\mathrm{T}}$ by GLC according to the procedures of Kämpfer \& Kroppenstedt (1996) showed that the profile consisted predominantly of $17: 1 \omega 6 c(43 \cdot 0 \%), 18: 1 \omega 7 c(9 \cdot 0 \%)$, 
Table 2. Major fatty acid content of Sphingopyxis reference strains and related organisms

Values are percentages of total fatty acids. Strains: 1, strain $\mathrm{W}-50^{\mathrm{T}}$; 2, Sphingopyxis macrogoltabida $\mathrm{IFO} 15033^{\mathrm{T}}$ (data from Kämpfer et al., 1997); 3, Sphingopyxis terrae IFO $15098^{\mathrm{T}}$ (Kämpfer et al., 1997); 4, Sphingomonas taejonensis JSS54 ${ }^{\mathrm{T}}$ (Lee et al., 2001). For unsaturated fatty acids, the position of the double bond can be located by counting from the methyl $(\omega)$ end of the carbon chain; cis is indicated by the suffix $c$; trans by the suffix $t$. Summed features represent groups of two or three fatty acids that cannot be separated by GLC with the MIDI system. Summed feature 3 contains one or more of the following fatty acids: $16: 1 \omega 7 c$ and iso $2-\mathrm{OH}$ 15:0. Summed feature 7 contains one or more of the following isomers: 19:1 $\omega 6 c, 19: 0$ cyclo $\omega 10 c$ and/or an unknown compound with an ECL of 18.846. The unknown fatty acids have no name listed in the peak library file of the MIDI system and therefore cannot be identified. ND, Not determined.

\begin{tabular}{|c|c|c|c|c|}
\hline Fatty acid & 1 & 2 & 3 & 4 \\
\hline \multicolumn{5}{|l|}{ Saturated fatty acids } \\
\hline $14: 0$ & ND & ND & ND & ND \\
\hline $15: 0$ & $7 \cdot 0$ & ND & $5 \cdot 9$ & $2 \cdot 3$ \\
\hline $16: 0$ & $5 \cdot 8$ & $12 \cdot 8$ & $4 \cdot 5$ & $23 \cdot 0$ \\
\hline $17: 0$ & $3 \cdot 8$ & ND & $3 \cdot 8$ & $1 \cdot 6$ \\
\hline \multicolumn{5}{|l|}{ Unsaturated fatty acids } \\
\hline $15: 1 \omega 6 c$ & $0 \cdot 4$ & ND & ND & ND \\
\hline $16: 1 \omega 5 c$ & $1 \cdot 2$ & $2 \cdot 9$ & $2 \cdot 1$ & $1 \cdot 6$ \\
\hline $17: 1 \omega 8 c$ & $6 \cdot 2$ & ND & $7 \cdot 9$ & $1 \cdot 8$ \\
\hline $17: 1 \omega 6 c$ & $43 \cdot 0$ & $4 \cdot 5$ & $48 \cdot 0$ & $11 \cdot 8$ \\
\hline $18: 1 \omega 7 c$ & $9 \cdot 0$ & ND & ND & ND \\
\hline $18: 1 \omega 5 c$ & $0 \cdot 4$ & $0 \cdot 9$ & $0 \cdot 6$ & ND \\
\hline 11-methyl $18: 1 \omega 7 c$ & $2 \cdot 8$ & ND & ND & ND \\
\hline \multicolumn{5}{|l|}{ Hydroxy fatty acids } \\
\hline 2-OH 14:0 & $1 \cdot 0$ & $3 \cdot 0$ & $0 \cdot 8$ & $4 \cdot 3$ \\
\hline 2-OH 15:0 & $7 \cdot 0$ & ND & $4 \cdot 9$ & $2 \cdot 3$ \\
\hline 2-OH 16:0 & 0.8 & $2 \cdot 9$ & ND & $1 \cdot 5$ \\
\hline \multicolumn{5}{|l|}{ Summed features } \\
\hline Summed feature 3 & $11 \cdot 4$ & $31 \cdot 8$ & $8 \cdot 0$ & $21 \cdot 5$ \\
\hline Summed feature 7 & $\mathrm{ND}$ & $41 \cdot 2$ & $13 \cdot 0$ & $28 \cdot 3$ \\
\hline
\end{tabular}

$15: 0(7 \cdot 0 \%), 16: 0(5.9 \%)$ and summed feature $3(16$ : $1 \omega 7 c$ and iso $2-\mathrm{OH} 15: 0,11.4 \%)$; hydroxylated fatty acids $(2-\mathrm{OH} 14: 0,1 \cdot 0 \% ; 2-\mathrm{OH} 15: 0,7 \cdot 0 \%$; and $2-\mathrm{OH}$ 16:0, $0 \cdot 8 \%$ ) were also present. Takeuchi et al. (2001) reported that the hydroxy fatty acid profiles provide valuable information for differentiation of the genera Sphingomonas, Sphingobium, Novosphingobium and Sphingopyxis. Species of the genus Sphingomonas sensu stricto contained 2-OH 14:0 and/or 2-OH 15:0 as the major components, whereas those of the genus Sphingopyxis were characterized by the presence of 2-

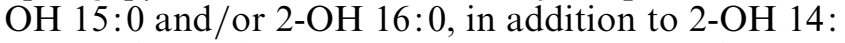
0 . Members of the genera Sphingobium and Novosphingobium contained 2-OH 14:0 only as the major component. The detailed fatty acid profile of strain $\mathrm{W}$ $50^{\mathrm{T}}$ is shown in Table 2 and clearly indicates allocation of this strain to the genus Sphingopyxis. A similar fatty acid profile has been described for other species of the genus Sphingopyxis, for which the major fatty acids were reported to be $18: 1$, saturated $16: 0$ and $16: 1$, and major hydroxylated fatty acids were 2-OH $14: 0$ and 2$\mathrm{OH}$ 15:0 and/or 2-OH 16:0 (Busse et al., 1999; Takeuchi et al., 2001).

Analysis of the respiratory lipoquinones of strain W$50^{\mathrm{T}}$ by HPLC (Tindall, 1990) gave one characteristic major peak $(92 \%)$, which corresponded to ubiquinone Q-10, and a smaller peak (8\%) that corresponded to ubiquinone Q-9. HPLC polyamine analysis (Busse \& Auling, 1988; Busse et al., 1997) with cells grown on R2A agar revealed a pattern characteristic for the genera Sphingobium, Novosphingobium and Sphingopyxis of the $\alpha$-Proteobacteria (Busse \& Auling, 1988; Busse et al., 1999). Strain W-50 ${ }^{\mathrm{T}}$ contained spermidine as major component $\left[12.9 \mu \mathrm{mol}(\mathrm{g} \text { dry wt })^{-1}\right]$, whereas cadaverine, putrescine and spermine were detected in only small amounts [respectively $0 \cdot 1,0 \cdot 2$ and $0 \cdot 3 \mu \mathrm{mol}$ (g dry wt $)^{-1}$ ]. 1,3-Diaminopropane was detected in trace amounts.

Polar lipid fingerprinting by two-dimensional TLC according to Denner et al. (2001) showed that strain $\mathrm{W}-50^{\mathrm{T}}$ possesses a sphingoglycolipid, clearly suggesting again that the bacterium belongs to the $\alpha-4$ subclass of the Proteobacteria. The overall polar lipid pattern of strain $\mathrm{W}-50^{\mathrm{T}}$ corresponded to those reported for sphingomonads (Busse et al., 1999), since it was composed of phosphatidylethanolamine, diphosphatidylglycerol, phosphatidylglycerol, phosphatidylcholine and sphingoglycolipid. Small amounts of phosphatidylmonomethylethanolamine, which has been detected in the majority of sphingomonads, were also present in strain $\mathrm{W}-50^{\mathrm{T}}$. However, a detailed comparison of the polar lipid composition of strain $\mathrm{W}-50^{\mathrm{T}}$ indicated several significant differences from those of its close relatives, Sphingopyxis macrogoltabida and Sphingopyxis terrae, including the presence of phosphatidylglycerol in small amounts and the absence of the unidentified unique polar lipid PL3 (phospholipid) and GL1 (glycolipid). The absence of unidentified glycolipids GL2 and GL4 and the occurrence of phosphatidylcholine in large amounts in strain $\mathrm{W}-50^{\mathrm{T}}$ further distinguish it from Sphingopyxis macrogoltabida, whereas strain $\mathrm{W}-50^{\mathrm{T}}$ can be distinguished from Sphingopyxis terrae by the lack of phosphatidyldimethylethanolamine.

The 16S rRNA gene was amplified by PCR using universal primers (5'-AGAGTTTGATYMTGGCTCAG, positions 7-26; 5'-CAKAAAGGAGGTGATCC, positions 1528-1544; both from Gibco BRL) and sequenced. Phylogenetic analysis was performed using the ARB software package (Ludwig \& Strunk, 1997). Distance matrix, maximum-parsimony and maximumlikelihood methods were applied for tree construction as implemented in the ARB software package (results not shown).

The $16 \mathrm{~S}$ rRNA sequence of strain $\mathrm{W}-50^{\mathrm{T}}$, with a continuous stretch of $1482 \mathrm{bp}$, was used to search 
GenBank and the Ribosomal Database Project. Strain $\mathrm{W}-50^{\mathrm{T}}$ is a member of the Sphingomonas sensu lato group, most closely related to the genus Sphingopyxis. Sequence similarity calculations indicated that the nearest relatives of strain $\mathrm{W}-50^{\mathrm{T}}$ are Sphingopyxis macrogoltabida IFO $15033^{\mathrm{T}}$ (accession no. D13723; 97.3\% sequence similarity), Sphingopyxis terrae IFO $15098^{\mathrm{T}}$ (D13727; $96 \cdot 3 \%$ similarity) and Sphingomonas taejonensis KCTC 2884 ${ }^{\mathrm{T}}$ (AF131297; 97.3\% similarity). Highest sequence similarity was detected to Sphingomonas adhaesiva IFO $15099^{\mathrm{T}}$ (accession no. D13722; 97.5\% similarity). However, it is most likely that this sequence was not derived from the type strain, and the probability of strain confusion, also supported by differences in polyamine patterns for the type strain of Sphingomonas adhaesiva from different strain collections, has recently been discussed in detail (Busse et al., 1999).

Although the $16 \mathrm{~S}$ rRNA sequence of strain $\mathrm{W}-50^{\mathrm{T}}$ was most closely related to that of Sphingomonas adhaesiva IFO $15099^{\mathrm{T}}$, it is nevertheless obvious from the results of chemotaxonomic and other phenotypic investigations that the two strains do not belong in the same species. DNA-DNA hybridization experiments were performed with strain $\mathrm{W}-50^{\mathrm{T}}$ and Sphingopyxis macrogoltabida IFO $15033^{\mathrm{T}}$, Sphingopyxis terrae IFO $15098^{\mathrm{T}}$, Sphingomonas adhaesiva IFO $15099^{\mathrm{T}}$ and Sphingomonas taejonensis KCTC $2884^{\mathrm{T}}$. Strains were grown overnight in nutrient broth. DNA was isolated according to the protocol of Wisotzkey et al. (1990) and quality controlled in a $1 \%$ agarose gel. Labelling of DNA, hybridizations and data analysis were performed as described by Ziemke et al. (1998) except that for nick-translation, $2 \mu \mathrm{g}$ DNA was labelled during $3 \mathrm{~h}$ incubation at $15^{\circ} \mathrm{C}$.

Strain $\mathrm{W}-50^{\mathrm{T}}$ showed relatively low DNA-DNA similarity values to the type strains of Sphingopyxis macrogoltabida (31.9\%) and Sphingopyxis terrae $(44.9 \%)$. The DNA-DNA similarities to Sphingomonas adhaesiva IFO $15099^{\mathrm{T}}$ and Sphingomonas taejonensis KCTC $2884^{\mathrm{T}}$ were respectively 17.9 and $31 \cdot 0 \%$. Pooled standard deviations of all hybridization experiments were between $4 \cdot 8$ and $6 \cdot 6 \%$.

The main reason for the creation of a novel species for strain $\mathrm{W}-50^{\mathrm{T}}$ is the rather high degree of sequence divergence of the $16 \mathrm{~S}$ rRNA gene in comparison with corresponding sequences from different species of the genus Sphingopyxis, in addition to DNA-DNA similarity values and several phenotypic properties that are clearly different from those of Sphingopyxis macrogoltabida, Sphingopyxis terrae and the recently described species Sphingomonas taejonensis.

In addition, strain $\mathrm{W}-50^{\mathrm{T}}$ can be distinguished from the two species of the genus Sphingopyxis on the basis of qualitative differences in polar lipid profiles (Fig. 1; Busse et al., 1999). It has been clearly shown recently by Lee et al. (2001) that the type strains of Sphingopyxis macrogoltabida and Sphingopyxis terrae, respectively

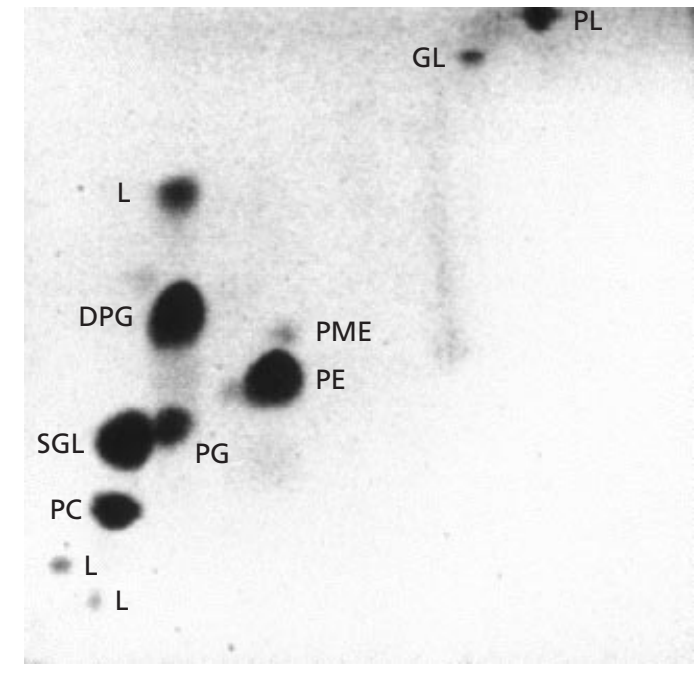

Fig. 1. Polar lipid fingerprint of strain $\mathrm{W}-50^{\top}$ after separation by two-dimensional TLC. Abbreviations: PE, phosphatidylethanolamine; PME, phosphatidylmonomethylethanolamine; PC, phosphatidylcholine; PG, phosphatidylglycerol; DPG, diphosphatidylglycerol; SGL, sphingoglycolipid; $G L$, unidentified glycolipid; PL, unidentified phospholipid; L, unidentified polar lipid. The TLC plate was sprayed with molybdatophosphoric acid.

sharing $16 \mathrm{~S}$ rRNA gene sequence similarities of $97 \cdot 7$ and $95.9 \%$ to Sphingomonas taejonensis, are distinct species on the basis of DNA-DNA pairing studies, with only 19 and $11 \%$ DNA-DNA similarity. In addition, it has been shown previously by Takeuchi et al. (1993) that Sphingopyxis macrogoltabida IFO $15033^{\mathrm{T}}$ and Sphingopyxis terrae IFO $15098^{\mathrm{T}}$ share DNA-DNA similarity of $27 \%$. These strains have a 16S rRNA sequence similarity of $96 \cdot 3 \%$.

On the basis of these results, strain $\mathrm{W}-50^{\mathrm{T}}$ can be described as a representative of a novel species of the genus Sphingopyxis, for which the name Sphingopyxis witflariensis sp. nov. is proposed.

\section{Description of Sphingopyxis witflariensis sp. nov.}

Sphingopyxis witflariensis (wit.fla.ri.en'sis. M.L. adj. witflariensis of Witflaria, referring to the German city of Wetzlar, from where the organism was first isolated).

Cells are straight rods, $0.5-0.8 \times 1 \cdot 0-2.0 \mu \mathrm{m}$. Cells occur singly and are motile, Gram-negative and oxidase- and catalase-positive, with an oxidative, chemoheterotrophic metabolism. Ubiquinone Q-10 $(92 \%)$ is the major respiratory lipoquinone type; small amounts of ubiquinone Q-9 (8\%) are also present. Spermidine is the major polyamine. Major polar lipids are phosphatidylethanolamine, diphosphatidylglycerol, phosphatidylcholine and sphingoglycolipid; small amounts of phosphatidylglycerol and phospha- 
tidylmonomethylethanolamine are also present. The fatty acids 17: $1 \omega 6 c, 18: 1 \omega 7 c, 15: 0,16: 0$ and summed feature $3(16: 1 \omega 7 c$ and iso $2-\mathrm{OH} 15: 0,11.4 \%)$ are produced, in addition to the three hydroxylated fatty acids 2-OH 14:0, 2-OH 15:0 and 2-OH 16:0. Colonies are circular, opaque, slightly raised and bright yellow with entire margins on standard bacteriological media. The visible absorption spectra of the yellow pigment (acetone extract) shows two peaks, at $\lambda_{\max } 452$ and $478 \mathrm{~nm}$, and a slight inflexion at $425 \mathrm{~nm}$. Growth occurs at $15-37^{\circ} \mathrm{C}$ on standard media such as Tryptone soy agar, nutrient agar or Luria-Bertani medium, as well as on the nutrient-reduced media R2A agar and PTYG agar. No growth occurs on MacConkey agar and Czapek-Dox agar. Does not grow at $42{ }^{\circ} \mathrm{C}$. Nitrate is not reduced to nitrite or $\mathrm{N}_{2}$. Tests for indole production, arginine dihydrolase, urease and $\mathrm{H}_{2} \mathrm{~S}$ are negative. Gelatin, starch and DNA are not hydrolysed. Acid is not produced from glucose, lactose, sucrose, D-mannitol, dulcitol, salicin, adonitol, inositol, sorbitol, L-arabinose, raffinose, L-rhamnose, maltose, D-xylose, trehalose, cellobiose, methyl Dglucoside, erythritol, melibiose, D-arabitol or D-mannose. The following compounds are utilized as sole sources of carbon: D-glucose, D-maltose, azelate, DL-3hydroxybutyrate, suberate, L-alanine, L-histidine, Lleucine and L-proline. The following compounds are not utilized as sole sources of carbon: $\mathrm{N}$ acetylgalactosamine, $\quad \mathrm{N}$-acetylglucosamine, $\quad$ Larabinose, L-arbutin, D-cellobiose, D-galactose, gluconate, $D$-mannose, $\alpha$-D-melibiose, L-rhamnose, Dribose, sucrose, salicin, D-trehalose, D-xylose, adonitol, $i$-inositol, D-sorbitol, glycerol, D-fructose, D-mannitol, maltitol, putrescine, cis-aconitate, trans-aconitate, 4aminobutyrate, citrate, mesaconate, acetate, propionate, adipate, fumarate, glutarate, itaconate, DLlactate, 2 -oxoglutarate, pyruvate, L-aspartate, $\beta$-alanine, L-ornithine, L-phenylalanine, L-serine, L-histidine, L-tryptophan, 3-hydroxybenzoate, 4-hydroxybenzoate and phenylacetate. L-Alanine $p \mathrm{NA}, \gamma-\mathrm{L}-$ glutamate $p \mathrm{NA}$, L-proline $p \mathrm{NA}, \quad p \mathrm{NP} \alpha$-D-glucopyranoside, bis- $p$ NP phosphate, bis- $p$ NP phosphorylcholine and 2-deoxythymidine-2'- $p$ NP phosphate are hydrolysed. The following compounds are not hydrolysed: $p$ NP $\beta$-D-galactopyranoside, $\mathrm{ONPG}, p \mathrm{NP}$ $\beta$-D-glucuronide, $p$ NP $\beta$-D-glucopyranoside and $p$ NP $\beta$-D-xylopyranoside. Susceptible to amoxycillin/ clavulanic acid, ampicillin, colistin sulfate, gentamicin, kanamycin, neomycin and polymyxin B. Resistant to bacitracin, chloramphenicol, furazolidone, fusidic acid, nitrofurantoin, penicillin $\mathrm{G}$, streptomycin and tetracycline. The type strain is strain $\mathrm{W}-50^{\mathrm{T}}(=\mathrm{DSM}$ $14551^{\mathrm{T}}=$ CIP $\left.107174^{\mathrm{T}}\right)$. Isolated from activated sludge of a wastewater plant in Wetzlar, Germany.

\section{Acknowledgements}

The authors are grateful for the expert technical assistance of Maria Sowinsky and Gundula Will. We also thank Dr Jung-Sook Lee for providing the type strain of Sphingomonas taejonensis.

\section{References}

Balkwill, D. L. \& Ghiorse, W. C. (1985). Characterization of subsurface bacteria associated with two shallow aquifers in Oklahoma. Appl Environ Microbiol 50, 5680-5688.

Busse, J. \& Auling, G. (1988). Polyamine pattern as a chemotaxonomic marker within the Proteobacteria. Syst Appl Microbiol 11, 1-8.

Busse, H.-J., Bunka, S., Hensel, A. \& Lubitz, W. (1997). Discrimination of members of the family Pasteurellaceae based on polyamine patterns. Int $J$ Syst Bacteriol 47, 698-708.

Busse, H.-J., Kämpfer, P. \& Denner, E. B. M. (1999). Chemotaxonomic characterisation of Sphingomonas. J Ind Microbiol Biotechnol 23, 242-251.

Denner, E. B. M., Paukner, S., Kämpfer, P., Moore, E. R. B., Abraham, W.-R., Busse, H.-J., Wanner, G. \& Lubitz, W. (2001). Sphingomonas pituitosa sp. nov., an exopolysaccharide-producing bacterium that secretes an unusual type of sphingan. Int J Syst Evol Microbiol 51, 827-841.

Gerhardt, P., Murray, R. G. E., Wood, W. A. \& Krieg, N. R. (1994). Methods for General and Molecular Bacteriology. Washington, DC: American Society for Microbiology.

Jenkins, C. L., Andrews, A. G., McQuade, T. J. \& Starr, M. P. (1979). The pigment of Pseudomonas paucimobilis is carotenoid (nostoxanthin), rather than a brominated aryl-polyene (xanthomonadin). Curr Microbiol 3, 1-4.

Kämpfer, P. \& Kroppenstedt, R. M. (1996). Numerical analysis of fatty acid patterns of coryneform bacteria and related taxa. Can $J$ Microbiol 42, 989-1005.

Kämpfer, P., Steiof, M. \& Dott, W. (1991). Microbiological characterization of a fuel-oil contaminated site including numerical identification of heterotrophic water and soil bacteria. Microb Ecol 21, 227-251.

Kämpfer, P., Denner, E. B. M., Meyer, S., Moore, E. R. B. \& Busse, H.-J. (1997). Classification of 'Pseudomonas azotocolligans' Anderson 1955,132 , in the genus Sphingomonas as Sphingomonas trueperi sp. nov. Int J Syst Bacteriol 47, 577-583.

Koskinen, R., Ali-Vehmas, T., Kämpfer, P., Laurikkala, M., Tsitko, I., Kostyal, E., Atroshi, F. \& Salkinoja-Salonen, M. (2000). Characterization of Sphingomonas isolates from Finnish and Swedish drinking water distribution systems. J Appl Microbiol 89, 687-696.

Lee, J.-S., Shin, Y. K., Yoon, J.-H., Takeuchi, M., Pyun, Y.-R. \& Park, Y.-H. (2001). Sphingomonas aquatilis sp. nov., Sphingomonas koreensis sp. nov., and Sphingomonas taejonensis sp. nov., yellow-pigmented bacteria isolated from natural mineral water. Int $J$ Syst Evol Microbiol 51, 1491-1498.

Ludwig, W. \& Strunk, O. (1997). ARB - a software environment for sequence data. http://www.mikrobiologie.tu-muenchen.de/pub/ ARB/documentation/arb.ps

Neef, A., Witzenberger, R. \& Kämpfer, P. (1999). Detection of sphingomonads and in situ identification in activated sludge using $16 \mathrm{~s}$ rRNA-targeted oligonucleotide probes. J Ind Microbiol Biotechnol 23, 261-267.

Pollock, T. J. (1993). Gellan-related polysaccharides and the genus Sphingomonas. J Gen Microbiol 139, 1939-1945.

Takeuchi, M., Kawai, F., Shimada, Y. \& Yokota, A. (1993). Taxonomic study of polyethylene glycol-utilizing bacteria: amended description of the genus Sphingomonas and new description of Sphingomonas macrogoltabidus sp. nov., Sphingomonas sanguis sp. nov., and Sphingomonas terrae sp. nov. Syst Appl Microbiol 16, 227-238.

Takeuchi, M., Hamana, K. \& Hiraishi, A. (2001). Proposal of the genus Sphingomonas sensu stricto and three new genera, Sphingobium, Novosphingobium and Sphingopyxis, on the basis of phylogenetic and chemotaxonomic analyses. Int J Syst Evol Microbiol 51, 1405-1417.

Tindall, B. J. (1990). Lipid composition of Halobacterium lacusprofundi. FEMS Microbiol Lett 66, 199-202.

White, D. C., Sutton, S. D. \& Ringelberg, D. B. (1996). The genus Sphingomonas: physiology and ecology. Curr Opin Biotechnol 7, 301-306. 
Wisotzkey, J. D., Jurtshuk, P., Jr \& Fox, G. E. (1990). PCR amplification of $16 \mathrm{~S}$ rDNA from lyophilized cell cultures facilitates studies in molecular systematics. Curr Microbiol 21, 325-327.

Yabuuchi, E., Yano, I., Oyaizu, H., Hashimoto, Y., Ezaki, T. \& Yamamoto, H. (1990). Proposals of Sphingomonas paucimobilis, gen. nov. and comb. nov., Sphingomonas parapaucimobilis sp. nov.,
Sphingomonas yanoikuyae sp. nov., Sphingomonas adhaesiva sp. nov., Sphingomonas capsulata comb. nov., and two genospecies of the genus Sphingomonas. Microbiol Immunol 34, 99-119.

Ziemke, F., Höfle, M. G., Lalucat, J. \& Roselló-Mora, R. (1998).

Reclassification of Shewanella putrefaciens Owen's genomic group II as Shewanella baltica sp. nov. Int J Syst Bacteriol 48, 179-186. 